\title{
Metschnikowia bicuspidata dominates in Taiwanese cold-weather yeast infections of Macrobrachium rosenbergii
}

\author{
Shih-Chu Chen ${ }^{1,2, *}$, Yu-Chin Chen ${ }^{1}$, Jimmy Kwang ${ }^{3}$, Ivanus Manopo ${ }^{3}$, \\ Pei-Chi Wang ${ }^{1,4}$, Hso-Chi Chaung ${ }^{1,2}$, Li-Ling Liaw ${ }^{5}$, Shih-Hau Chiu ${ }^{5}$ \\ ${ }^{1}$ Department of Veterinary Medicine, ${ }^{2}$ Graduate Institute of Animal Vaccine Technology, and \\ ${ }^{4}$ Department of Tropical Agriculture and International Cooperation, National Pingtung University of Science and \\ Technology, Pingtung 912, Taiwan, ROC \\ ${ }^{3}$ Animal Health Biotechnology Group, Temasek Life Sciences Laboratory, 1 Research Link, \\ National University of Singapore, Singapore 117604, Singapore \\ ${ }^{5}$ Bioresources Collection and Research Center, Food Industry Research and Development Institute, Hsinchu 300, \\ Taiwan, ROC
}

\begin{abstract}
At water temperatures below $17^{\circ} \mathrm{C}$, yeast infections often occurred in 6 to 11 mo old giant freshwater prawn Macrobrachium rosenbergii $(8$ to $12 \mathrm{~cm}$ ) in Taiwan from May 2001 to December 2003, with a cumulative mortality of 20 to $95 \%$. Gross signs of disease included milky hemolymph, a yellow exoskeleton, opaque muscles, and a swollen hepatopancreas (HP). Histopathology included marked edema and extensive necrotic lesions associated with large numbers of yeast aggregates and inflammation within the muscles, HP, and other internal organs such as the heart, ovary, and intestine. Yeast cell numbers isolated from various tissues ranged from $4.5 \times 10^{8}$ to $9.0 \times 10^{9}$ colony forming units (CFU) per $100 \mathrm{mg}$. From diseased prawns from 12 affected farms, the presence of Metschnikowia bicuspidata ( $98.4 \%$ prevalence), Saccharomyces cerevisiae ( $0.8 \%$ prevalence), and Candida albicans ( $0.8 \%$ prevalence) was confirmed by biochemical tests and sequencing of PCR products from the D1/D2 domain of 26S rDNA. Experimental infection with these isolates caused gross signs and histopathological changes similar to those observed in naturally infected prawns, and lethal doses $\left(\mathrm{LD}_{50}\right)$ were $3.8 \times 10^{3}$, $2.0 \times 10^{3}$, and $4.3 \times 10^{3} \mathrm{CFU} \mathrm{prawn}^{-1}$, respectively. Although the results of this study revealed that $\mathrm{M}$. bicuspidata may be the major cause of yeast infections in the giant freshwater prawns in Taiwan, this is the first time that $S$. cerevisiae and C. albicans are also reported as pathogens.
\end{abstract}

KEY WORDS: Giant freshwater prawn - Macrobrachium rosenbergii - Metschnikowia bicuspidata Saccharomyces cerevisiae $\cdot$ Candida albicans $\cdot$ Pathogenicity $\cdot$ PCR $\cdot$ Phylogenetic analysis

\section{INTRODUCTION}

Intensification of aquaculture production of the giant freshwater prawn Macrobrachium rosenbergii has led to serious disease outbreaks in Taiwan where prawn production declined by 47 to $52 \%$ from 1992 to 1995 (New 1995). Two separate diseases have been associated with the decline in production. The first disease, caused by the bacterial pathogen Lactococcus garvieae, mainly occurs during summer (June to September) and induces muscle opacity and necrosis (Chen et al. 2001). The second disease is caused by a yeast that produces gross signs of a swollen hepatopancreas (HP), milky hemolymph, a yellow exoskeleton, and opaque or whitish muscles (Lu et al. 1998, Chen et al. 2003). Yeast-related disease outbreaks have occurred in southern Taiwan from 1988 to 1994, mostly during cool weather (October to March) but especially (64\%) during the winter (December to February; Lu et al. 1998). Yeasts that have been reported to be pathogenic for M. rosenbergii include Candida sake, Pichia anoma, Endomyces fibuliger, and C. famata (Lu et al. 1998), as well as Metschnikowia bicuspidata in a co-infection with Enterococcus faecium (Chen et al. 2003). A 
pathogenic strain of $M$. bicuspidata var. australis has also been reported in brine shrimp Artemia salina (Spencer et al. 1964, Lachance et al. 1976); moreover, M. zobellii sp. nov. and M. krissii sp. nov., 2 yeasts from the Pacific Ocean, are pathogenic for Daphnia magna (Van Uden \& Castelo-Branco 1961).

The purpose of the present study was to examine prawns from 12 farms showing gross signs of yeast infections in order to determine the prevalence of various yeast pathogens. Yeast identification was accomplished using API 32C kits, conventional biochemical tests, and molecular methods including a phylogenetic analysis.

\section{MATERIALS AND METHODS}

Prawn samples. Diseased prawns were collected and placed in plastic bags with water and aeration, and transported to the laboratory within $1 \mathrm{~h}$. For histopathological and microbiological analysis, 10 diseased prawns, (body weight 5 to $12 \mathrm{~g}$, length 8 to $12 \mathrm{~cm}$ ) were collected from each of 12 affected prawn farms during disease outbreaks between May 2001 and December 2003. Prawn mortality reached $95 \%$ in some ponds, with average losses around $35 \%$. The prawns were processed immediately upon reaching the laboratory.

Microbiology. For each diseased prawn, procedures and pathogen isolations followed the methods previously described by Chen et al. (2003) except for the use of yeast mold (YM) agar (Difco) instead of LowensteinJensen medium for yeast isolation. Isolated yeasts were primarily identified by PCR amplification and sequencing of rDNA (see 'Amplification and sequencing' below), but additional biochemical tests were carried out using API 32C kits for yeasts and ID32 Strep kits for bacteria (bioMérieux S.A.) combined with conventional biochemical tests including tolerance to different concentrations of sodium chloride and survivability at various temperatures (Lu et al. 1998, Chen et al. 2001, 2003).

Yeast counts from diseased prawns. Individual $100 \mathrm{mg}$ samples of hemolymph, muscle, gill, and HP were collected from 12 severely diseased prawns from 3 different prawn farms and then individually homogenized with an equal volume of sterile $\left(121^{\circ} \mathrm{C}, 15\right.$ min) distilled water. Yeast numbers were determined by plating serial 10-fold dilutions of each tissue homogenate $\left(10^{0}\right.$ to $\left.10^{-10}\right)$ on YM agar and reading at $48 \mathrm{~h}$ post inoculation.

Histopathology. Muscle tissue, HP tissue, and tissue with lesions from other internal organs such as the heart, ovary, and intestine were preserved in Davidson's fixative and processed for standard paraffin sectioning. Sections were stained with hematoxylin and eosin (H\&E) and periodic acid-Schiff (PAS) followed by light microscopy (Lu et al. 1998, Chen et al. 2003).

Electron microscopy. For transmission electron microscopy (TEM), the HP and heart were fixed with $2.5 \%$ glutaraldehyde in $0.2 \mathrm{mM}$ sodium cacodylate and post-fixed in $1 \%$ osmium tetroxide in $0.2 \mathrm{mM}$ sodium cacodylate. Sections were stained with uranyl acetate and lead citrate before examination. For scanning electron microscopy (SEM), yeast-infected tissues were fixed overnight with a final concentration of $2 \%$ glutaraldehyde in cacodylate buffer $(0.1 \mathrm{M}, \mathrm{pH} 7.2 ; \mathrm{Lu}$ et al. 1997). After fixation, the tissues were washed 5 times using the same buffer. Tissues were then dehydrated using increasing acetone concentrations from 30 to $100 \%$. The tissues were subjected to critical point drying and then sputter-coated with a layer of platinum palladium. Finally, samples were examined using TEM (Hitachi H-7500) and SEM (Hitachi S$3000 \mathrm{~N})$.

Yeast strains. For PCR assays, yeast strains that served as reference controls and 29 isolates purified from diseased Macrobrachium rosenbergii are listed in Table 1.

Amplification and sequencing of the D1/D2 domain of 26S rDNA. DNA isolation and PCR amplification followed the methods of Kurtzman \& Robnett (1997) and Chen et al. (2003). The PCR amplicons were sequenced directly from both strands of the DNA for each strain using a model 377 automatic DNA sequencer (Applied Biosystems). The resulting 26S rDNA sequences were aligned with representative sequences from GenBank, DDBJ, and EMBL databases (Chen et al. 2001). To prepare phylogenetic trees, CLUSTAL X software ver. 1.81 was used with the minimum evolution (Rzhetsky \& Nei 1993), maximumparsimony (MP; Fitch 1972), and neighbor-joining (NJ; Saitou \& Nei 1987) treeing algorithms. Evolutionary distance matrices for the minimum evolution, MP, and NJ methods were generated according to Jukes \& Cantor (1969). The computer program MEGA2 (Kumar et al. 2001) was used for all analyses. The resultant tree topologies were evaluated by bootstrap analyses (Felsenstein 1985) of the NJ method based on 1000 resamplings.

Experimental infections. Prawns Macrobrachium rosenbergii (3.5 to $4.5 \mathrm{~g}$ body weight) were obtained from a prawn farm in Pingtung, Taiwan. To ensure freedom from yeast and bacterial infections, 10 of 330 prawns were subjected to microbiological and histological examination by the same methods as described for microbiology and pathology above. The absence of bacteria or yeast growth on tryptic soy (TS), brain heart infusion (BHI), and YM agar and the absence of significant lesions in tissue sections from these prawns ensured freedom from bacterial and yeast infections at 
Table 1. Biochemical characteristics of yeast isolates from diseased Macrobrachium rosenbergii compared to the characteristics of reference strains. All grew on brain heart infusion (BHI) agar and on yeast mold (YM) agar at 10 to $25^{\circ} \mathrm{C}$ but none grew at 5 or $37^{\circ} \mathrm{C}$. +: positive growth; -: negative growth. 27MB: our 27 Metschnikowia bicuspidata isolates; C37: our Candida albicans isolate; Mry-2: our Saccharomyces cerevisiae isolate; MB: M. bicuspidata Bioresources Collection Research Center, Taiwan (BCRC) 21466; CA: C. albicans BCRC 21538; SC: S. cerevisiae BCRC 20270; PE: Pichia etchellsii BCRC 21479; CS: C. sake BCRC 21621; MK: M. krisii BCRC 22845; MR: M. reukaufii BCRC 22846

\begin{tabular}{|c|c|c|c|c|c|c|c|c|c|c|}
\hline Test & $27 \mathrm{MB}$ & C37 & Mry-2 & MB & $\mathrm{CA}$ & $\mathrm{SC}$ & $\mathrm{PE}$ & $\mathrm{CS}$ & MK & MR \\
\hline Sorbitol & + & + & - & + & + & - & + & + & - & + \\
\hline D-xylose & - & + & - & - & + & - & + & + & - & - \\
\hline Ribose & - & - & + & - & - & + & - & - & - & + \\
\hline Glycerol & - & - & - & + & - & - & + & + & - & + \\
\hline Rhamnose & - & - & - & - & - & - & - & - & - & - \\
\hline Palatinose & + & + & - & + & + & - & + & - & + & + \\
\hline Erythritol & - & - & - & - & - & - & - & - & - & - \\
\hline Melibose & - & - & - & - & - & - & - & - & - & - \\
\hline Glucoronate & - & - & - & - & - & - & - & - & - & - \\
\hline Melezitose & + & - & - & - & - & - & + & - & - & + \\
\hline Gluconate & $1 / 27^{a}$ & + & - & + & - & - & - & + & - & + \\
\hline Levulinate & - & - & - & + & - & - & - & - & - & - \\
\hline Glucose & + & + & + & + & + & + & + & + & - & + \\
\hline Sorbose & + & - & - & + & - & - & + & + & - & - \\
\hline Glucosamine & - & + & - & + & + & - & - & - & - & + \\
\hline Esculine & + & - & + & + & - & + & + & - & + & - \\
\hline Galactose & $7 / 27^{a}$ & + & + & - & + & + & - & - & - & + \\
\hline Actidione & - & + & - & - & + & - & - & - & - & - \\
\hline Sucrose & + & + & + & + & + & + & + & - & + & + \\
\hline N-Al-glucosamine & + & + & - & + & + & - & + & - & - & + \\
\hline DL-lactate & - & - & - & - & - & - & - & - & - & - \\
\hline L-arabinose & - & - & - & - & - & - & - & - & - & - \\
\hline Cellobiose & + & - & - & + & - & - & - & - & + & + \\
\hline Raffinose & - & - & + & - & - & + & - & - & - & - \\
\hline Maltose & + & + & + & + & + & + & + & - & + & + \\
\hline Trehalose & + & + & - & + & + & - & - & + & + & + \\
\hline 2-Keto-gluconate & + & + & - & + & + & - & + & + & - & + \\
\hline Methyl-D-glucoside & + & + & - & - & + & - & + & - & + & + \\
\hline Mannitol & + & + & - & + & + & - & + & + & + & + \\
\hline Lactose & - & - & - & - & - & - & - & - & - & - \\
\hline Inositol & - & - & - & + & - & - & - & - & - & - \\
\hline $\mathrm{NaCl} 0 \%$ & + & + & + & + & + & + & + & + & + & + \\
\hline $\mathrm{NaCl} 1-10 \%$ & + & + & + & + & + & - & + & + & + & - \\
\hline
\end{tabular}

$26 \%$ in the population sampled with $95 \%$ confidence (Cameron 2002). Healthy prawns $(\mathrm{n}=320)$ were acclimated to laboratory conditions by being held in 3 continuously aerated $400 \mathrm{l}$ aquaria containing $300 \mathrm{l}$ of fresh water at $25^{\circ} \mathrm{C}$ for $7 \mathrm{~d}$. The prawns were fed twice daily using a commercial prawn diet (Prawn Diet, Gold Brand Feed). Waste from each tank was removed daily. Subsequently, 152 uniformly sized prawns were subdivided into 19 groups containing 8 prawns each. Serial 10 -fold dilutions $\left(10^{0}\right.$ to $\left.10^{-5}\right)$ from microbial turbidity (optical density [OD] = 1 at $610 \mathrm{~nm}$ ) were prepared in sterile normal saline $(0.85 \% \mathrm{NaCl})$ using isolates of Metschnikowia bicuspidata, Saccharomyces cerevisiae, and Candida albicans. A dose of $0.1 \mathrm{ml}$ of each dilution was injected intramuscularly (IM) into 8 prawns from each treatment group (Groups 1 to 6 with M. bicuspidata, 7 to 12 with S. cerevisiae, and 13 to 18 with $C$. albicans). Sterile $\left(121^{\circ} \mathrm{C}, 15 \mathrm{~min}\right)$ normal saline $(0.85 \% \mathrm{NaCl})$ was injected IM $(0.1 \mathrm{ml})$ into 8 prawns from control Group 19. Following injection, each group was maintained separately in an $80 \mathrm{l}$ aquarium under the same conditions as described above for acclimation. The prawns were continuously monitored for morbidity and mortality for $10 \mathrm{~d}$ post inoculation and then sampled for histopathology and microbiology. The lethal dose $\left(\mathrm{LD}_{50}\right)$ of each treatment group was calculated based on the methods described by Stewart-Tull et al. (1984). 


\section{RESULTS}

\section{Clinical signs and gross pathology of diseased prawns from sampled farms}

Most moribund naturally infected prawns appeared to be inactive and anorexic and were found to be swimming near the pond edge. The disease spread rapidly, and mass mortality occurred within 5 to $10 \mathrm{~d}$ after the onset of clinical symptoms. Additional gross signs of disease included yellowish-brown body color, swelling between the cephalothorax and abdomen, a swollen HP, milky hemolymph, and opaque, whitish muscle tissue (Figs. 1 \& 2). Smears from milky hemolymph, epidermis, muscle, and HP displayed various

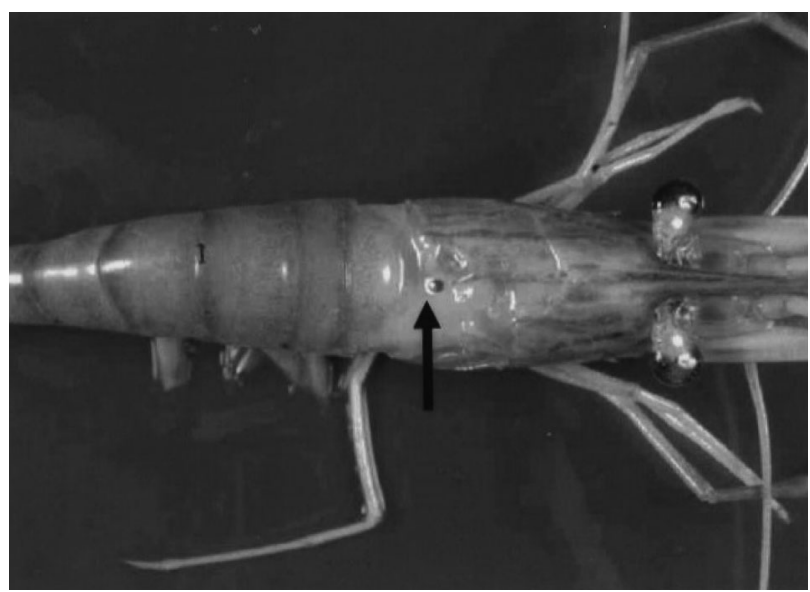

Fig. 1. Macrobrachium rosenbergii. Giant freshwater prawn with swollen cephalothorax, milky hemolymph (arrow), and whitish muscle

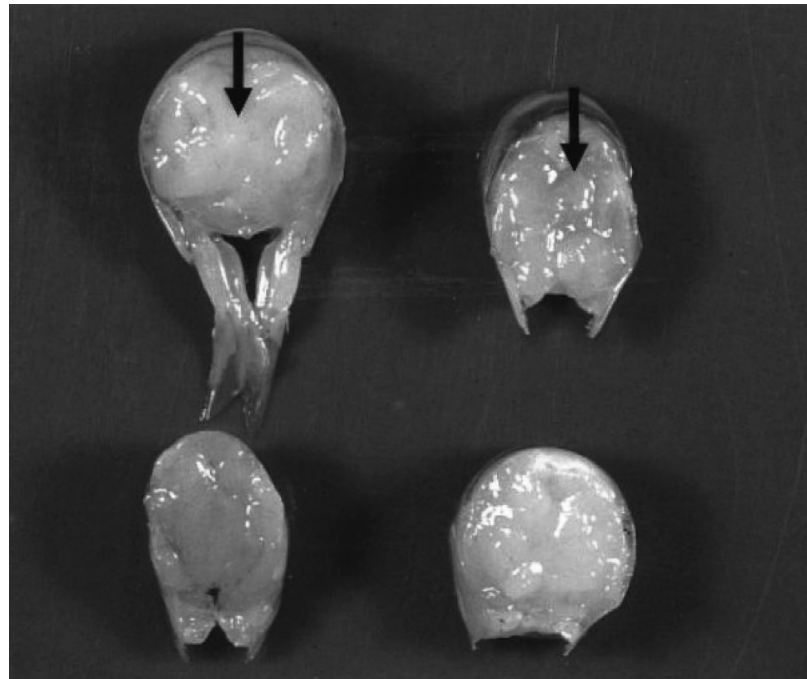

Fig. 2. Macrobrachium rosenbergii. On sectioning, whitish muscle (upper) and normal uninfected muscle (lower) are seen in an abdominal segment yeast growth stages ranging from 0.3 to $0.6 \mu \mathrm{m}$ in diameter. Small pieces of fresh tissues from diseased prawns exhibited large quantities of Gram-positive yeast cells by light microcopy.

\section{Histopathology of diseased prawns from farms}

Moribund prawns displayed an accumulation of edematous fluid between the cuticle and muscle. Infiltration of the cuticle, epidermis, and dermis by large numbers of yeast cells was also observed. Yeast cells were widely distributed throughout the muscle fiber and caused lysis and necrosis of myocytes. The muscle fibers exhibited various degenerative changes such as vacuolization and granulation as well as yeast aggregations (Fig. 3). In the $\mathrm{HP}$, the sinuses exhibited large clumps of yeast surrounded by thin membranes (Fig. 4). Large necrotic foci containing yeast clumps and cellular debris were also observed in the sinuses. Some prawns also displayed desquamation of the HP tubule epithelial cells producing mixed cellular debris and yeast cells.

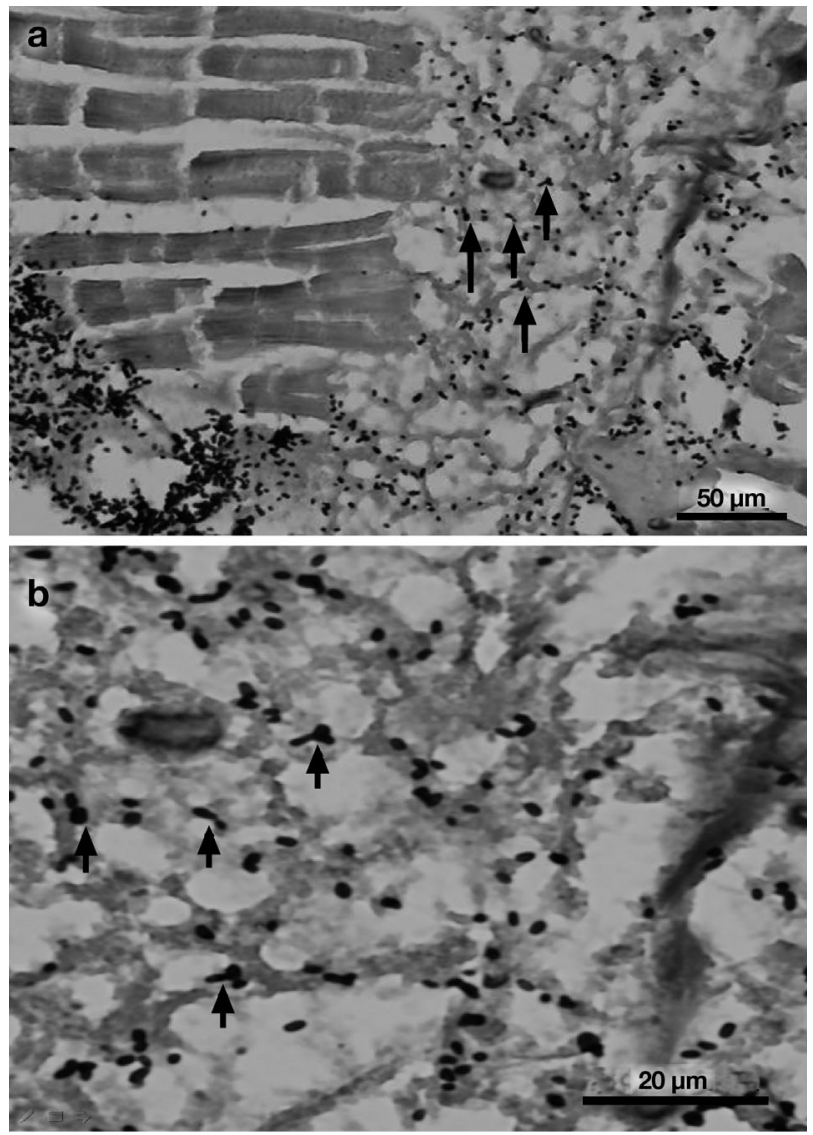

Fig. 3. Macrobrachium rosenbergii. (a,b) Tissue section showing vacuolization and fragmentation of muscle bundles, and yeast microcolonies (arrows) in the muscle. (b) Detail of the area indicated by arrows in (a) 

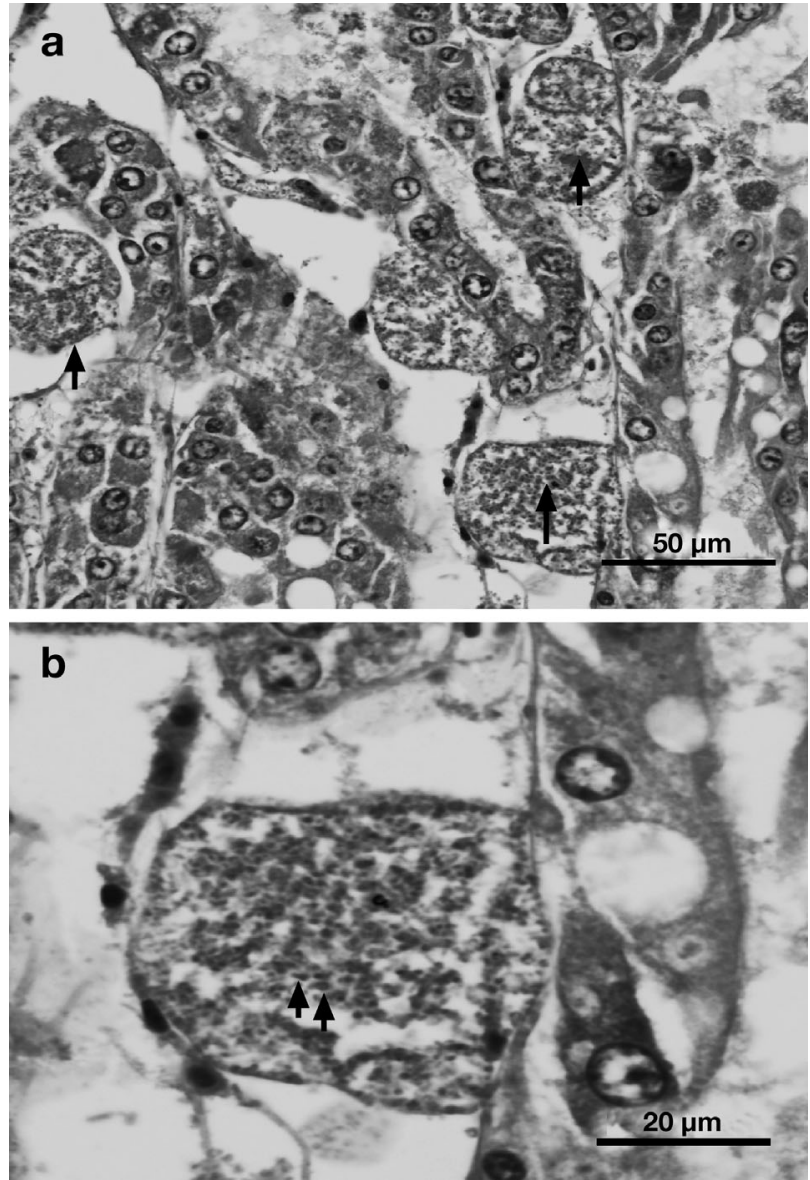

Fig. 4. Macrobrachium rosenbergii. (a,b) Section of infected prawn hepatopancreas showing vaculization of heoatoprancreatic tubular epithelial cells and yeast microcolonies (arrows) in

the sinus. (b) Detail of the area indicated by arrows in (a)

\section{Electron microscopy}

Large numbers of yeast aggregates were surrounded by a membrane-bound vacuole. Membrane-bound yeast aggregates were also present in the cytoplasm of other infected cells including gills, muscle, heart, and hemocytes. Moreover, enveloped yeast cell aggregates were present in the sinuses of the HP (Fig. 5), heart, and muscle. Yeast cells were detected in sinuses, in the cytoplasm of hemocytes (Fig. 6) and HP tubule epithelium. Degenerative and necrotic hemocytes with intracytoplasmic yeast were also revealed.

\section{Microbiology of farmed prawns}

Yeast colonies in samples from the muscle and HP appeared 1 to $2 \mathrm{~d}$ following culture on TS, BA, BHI, and YM agar. Yeast cells were quantified via plate counts of serial 10-fold dilutions from the hemolymph
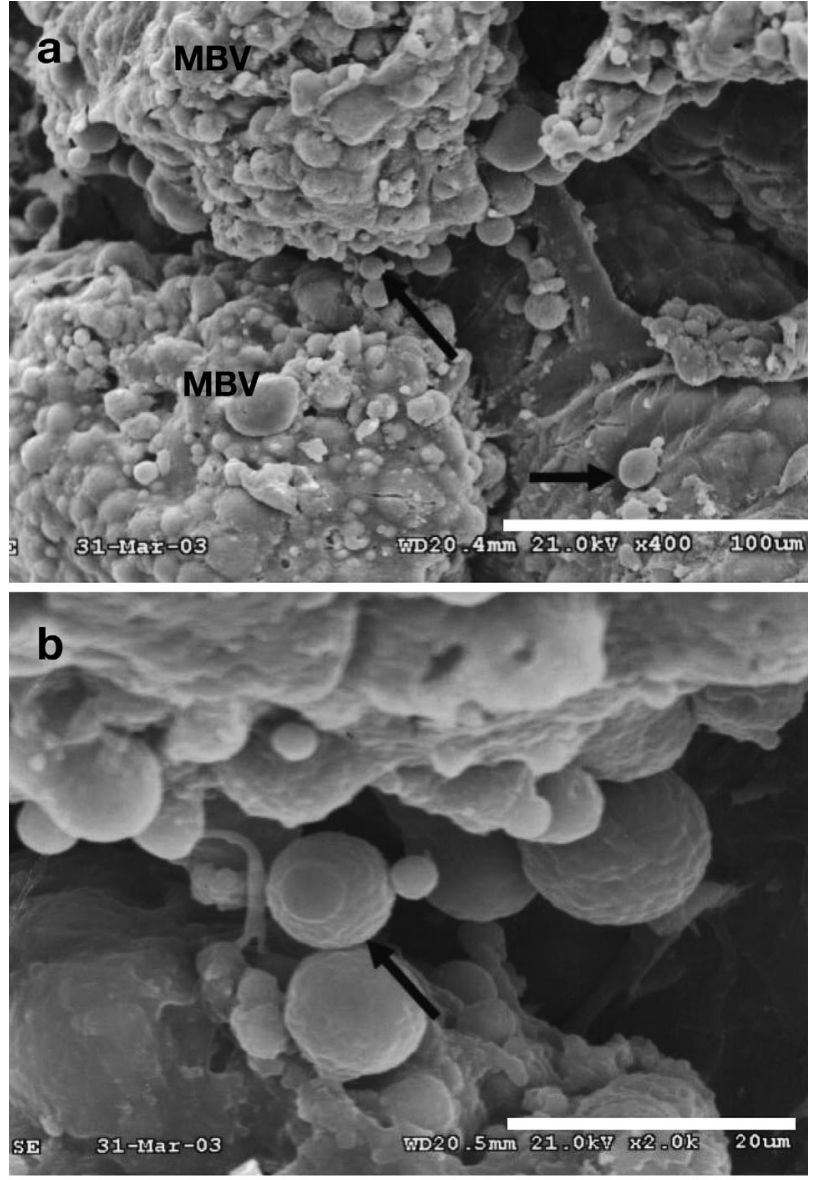

Fig. 5. Macrobrachium rosenbergii. (a) Scanning electron micrograph showing yeast aggregated within membranebound vacuoles (MBV) and a single yeast cell (arrows) in the hepatopancreas sinus. Scale bar $=100 \mu \mathrm{m}$. (b) Higher magnification of (a) showing yeast cell (arrow). Scale bar $=20 \mu \mathrm{m}$

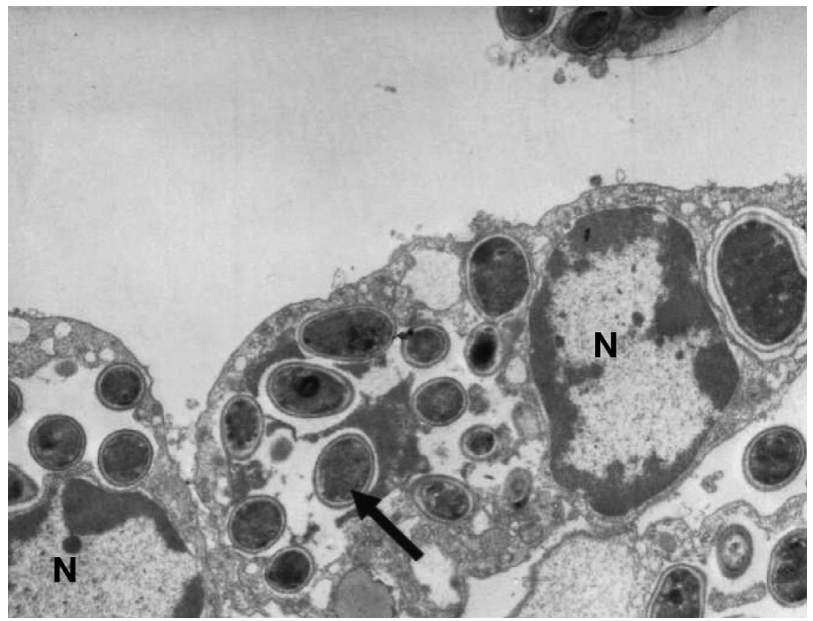

Fig. 6. Transmission electron micrograph of hemocytes with intracytoplasmic yeast (arrow) detected in the sinus of the hepatopancreas of a Macrobrachium rosenbergii. N: nucleus. $(\times 5000)$ 
or organs of 12 severely diseased prawns. The average number of yeast cells from the hemolymph, HP, muscle, and gills were $9.0 \times 10^{9}\left(5.0 \times 10^{8}\right.$ to $\left.1.9 \times 10^{11}\right)$, $4.9 \times 10^{9}\left(1.2 \times 10^{8}\right.$ to $\left.2.0 \times 10^{10}\right), 8.0 \times 10^{8}\left(7.0 \times 10^{6}\right.$ to $\left.3.4 \times 10^{9}\right)$, and $4.5 \times 10^{8}\left(3.2 \times 10^{5}\right.$ to $\left.3.0 \times 10^{9}\right) \mathrm{CFU}$ per $100 \mathrm{mg}$, respectively. The yeast colonies were observed following incubation on BHI agar. The colonies were initially small and transparent at $24 \mathrm{~h}$, but grew to $0.1-0.3 \mathrm{~cm}$ in diameter and became opaque or milky-white following continued incubation for $48 \mathrm{~h}$. The cells from these colonies were Grampositive and exhibited typical yeast morphology $(0.3 \times$ $0.6 \mu \mathrm{m}$ ) under light microscopy (Fig. 7).

Of 10 prawns collected from each of 12 farms (120 diseased prawns), 118 gave yeast colonies of a single type for each prawn while 2 gave yeast colonies of a single type together with bacterial colonies of a single type. One colony of each type was selected from each prawn for 26S rDNA-PCR followed by sequencing. This revealed that 116 of the yeast-only isolates were Metschnikowia bicuspidata while the other 2 were Saccharomyces cerevisiae and Candida albicans. For the 2 mixed isolations, the yeast was $M$. bicuspidata and the bacterium was Lactococcus garvieae. Thus, the prevalence for $M$. bicuspidata infections alone was $96.7 \%(116 / 120)$ and $0.8 \%(1 / 120)$ each for S. cerevisiae and $C$. albicans alone. The total was $98.3 \%$ $(118 / 120)$ prevalence for single yeast infections and $98.3 \%(118 / 120)$ for all infections (single or mixed) that contained $M$. bicuspidata.

Since it was not possible to carry out detailed biochemical analysis of yeasts from all diseased prawns, 27 isolates ( 2 or 3 prawn isolates from each farm) of Metschnikowia bicuspidata (AOD081, AOD154-1, AOD154-2, AOD163, AOD165, AOD166, AOD180,

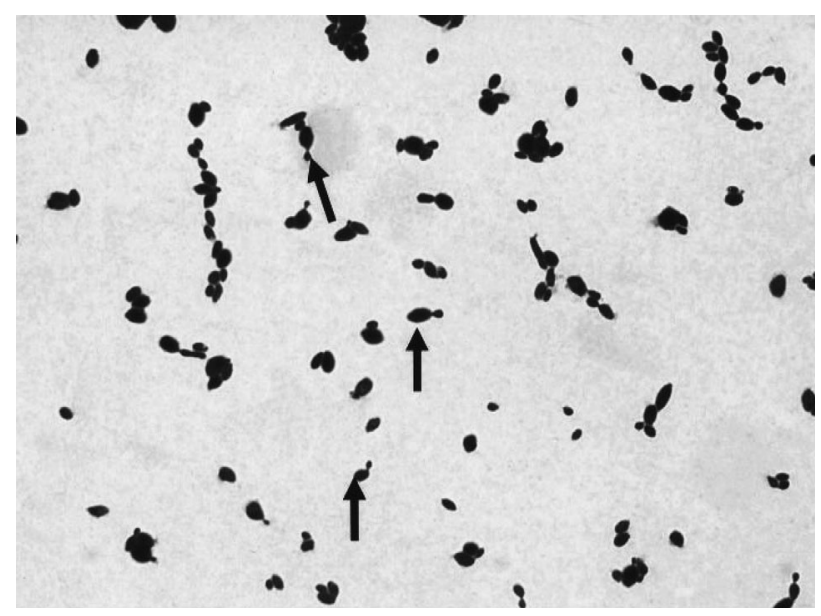

Fig. 7. Smear from a yeast colony that was derived from diseased Macrobrachium rosenbergii muscle that appeared $48 \mathrm{~h}$ after culture on YM agar. Smear shows different growth stages of yeast (arrows). (Gram stain, $\times 1000$ )
AOD181, AOD192, AOD208, C9, C11, C12, C13, C14, C15, C17, C42, C43, D21, D22, D23, D24, M4, M5, Mry-1, and Mry-3), Saccharomyces cerevisiae (Mry-2), and Candida albicans (C37) were selected for detailed biochemical and physiological tests and for comparison with reference strains of $S$. cerevisiae Bioresources Collection Research Center, Taiwan (BCRC) 20270; $M$. bicuspidata BCRC 21466; Pichia etchellsii BCRC 21479; C. albicans BCRC 21538; C. sake BCRC 21621; M. krisii BCRC 22845, and M. reukaufii BCRC 22846. All 29 isolates grew well on BHI and YM agar and exhibited Gram-positive yeast forms. Moreover, all grew over a wide concentration of $\mathrm{NaCl}(0$ to $10 \%)$ and narrow temperature range $\left(10\right.$ to $\left.25^{\circ} \mathrm{C}\right)$ with no growth occurring at temperatures $<5$ or $>37^{\circ} \mathrm{C}$.

The biochemical properties of the 27 Metschnikowia bicuspidata isolates (grouped together in the 'Test' column of Table 1) were almost identical to those of the reference strain $M$. bicuspidata BCRC 21466 (MB, Table 1). Minor differences in the assimilation ability of some isolates included glycerol, gluconate, levulinate, methyl-D-glucoside, and galactose. The biochemical characteristics of isolates of Saccharomyces cerevisiae (Mry-2) and Candida albicans (C37) were markedly different from those of $M$. bicuspidata. The profile of $C$. albicans (C37; Table 1) was virtually identical to that of reference strain C. albicans BCRC 21538, although there was a minor difference for gluconate. The profile of $S$. cerevisiae (Mry2) was identical to that of the reference strain S. cerevisiae BCRC 20270, except that Myr2 was tolerant to $\mathrm{NaCl}$ up to $10 \%$ while BCRC 20270 could not tolerate even $1 \% \mathrm{NaCl}$. The bacteria from 2 prawns with dual infections (yeast and bacteria) were identified as Lactococcus garvieae by rapid ID 32Strep.

\section{S rDNA sequences}

Fig. 8 shows a representative agarose gel following electrophoresis of PCR amplicons from the 26S rDNA gene of 16 of the 29 yeast isolates. The band for a $550 \mathrm{bp}$ amplicon was identical to those for the reference strains Metschnikowia bicuspidata BCRC 21466 and $M$. krisii BCRC 22845. The amplicon sequences for our $27 \mathrm{M}$. bicuspidata isolates fell into 2 groups that differed by only $3 \mathrm{bp}$, and a representative sequence for each group was deposited in GenBank. The first group (15 yeast isolates) had the GenBank accession numbers AY513692 to AY513705 and AY513707; and the second group (12 yeast isolates) had the accession numbers AF513707, AF513708, AF529297, AY509251, AY512575 to AY512580, AY513240, and AY513241. These 2 representative sequences were used for phylogenetic tree construction (see 'Phylogenetic analysis' 


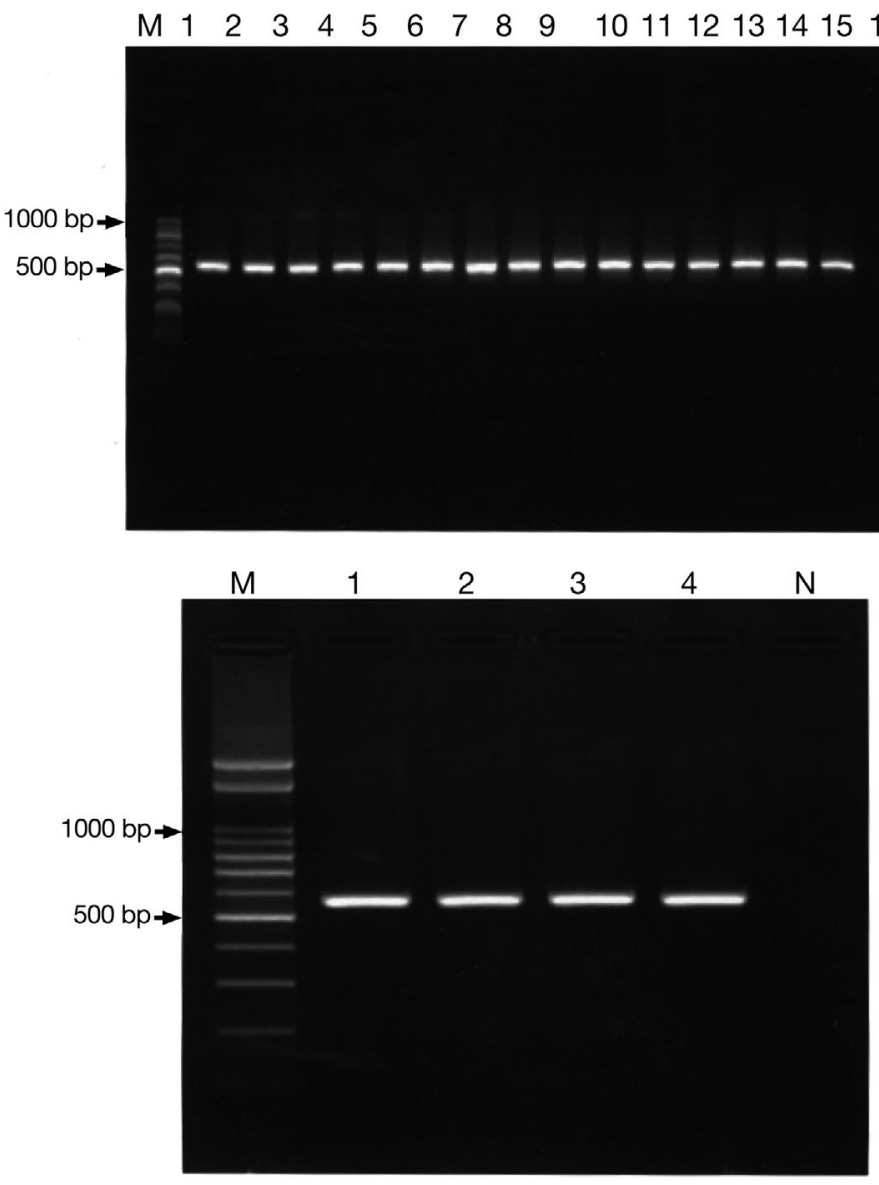

Fig. 8. Agarose gel (2\%) of PCR products from the 26S rDNA D1/D2 domain of yeasts stained with ethidium bromide. (a) Lane M: DNA molecular weight marker; Lane 1: Metschnikowia bicuspidata CCRC21466; Lane 2: C9; Lane 3: C12; Lane 4: C17; Lane 5: C42; Lane 6: C43; Lane 7: D22; Lane 8: D23; Lane 9: AOD154-1; Lane 10: AOD 154-2; Lane 11: AOD163; Lane 12: AOD181; Lane 13: AOD192; Lane 14: Mry1; Lane 15: Mry-3; Lane 16: negative control. (b) Lane M: DNA molecular weight marker; Lane $1: M$. bicuspidata CCRC21466; Lane 2: M. krisii 22845; Lane 3: AOD081; Lane 4: AOD 208; Lane N: negative control

below). They exhibited identities of 97 to $99 \%$ with $M$. bicuspidata (GenBank U44822), 96 to $98 \%$ with $M$. bicuspidata (GenBank. U94944), 95 to $97 \%$ with $M$. bicuspidata (GenBank U84238), 88 to $94 \%$ with $M$. australis (GenBank U44824), 90\% with M. reukaufii (GenBank AF406920), 90 to 95\% with M. zobellii (GenBank U44823), 90 to $95 \%$ with Candida magnifica (GenBank U44821), 91 to 93 \% with C. kofuensis (GenBank AF158019), and 90\% with C. magnifica (GenBank U44821). The amplicon sequences for C37 and Mry-2 were also deposited in GenBank and displayed an identity of $100 \%$ with C. albicans (GenBank AF45776) and Saccharomyces cerevisiae (GenBank AF53879 or AF 130345), respectively.

\section{Phylogenetic analysis}

One representative sequence each (GenBank AF529297 and AY513692) from our 2 groups of Metschnikowia bicuspidata isolates, reference sequences of $M$. bicuspidata (GenBank U94944, U44822, and U84238), and other reference sequences (Fig. 9) were aligned using CLUSTAL X software ver. 1.81. The evolutionary tree based on NJ methods (Fig. 9) revealed that our 2 groups of isolates aligned closely with other $M$. bicuspidata reported in GenBank. Similarly, our Saccharomyces cerevisiae isolate Mry-2 and Candida albicans isolate C37 aligned with S. cerevisiae (GenBank U45776) and C. albicans (GenBank AY 130345), respectively.

\section{Experimental infections}

The $\mathrm{LD}_{50}$ for 3 isolates, Metschnikowia bicuspidata, Saccharomyces cerevisiae, and Candida albicans, were $3.8 \times 10^{3}, 2.0 \times 10^{3}$, and $4.3 \times 10^{3} \mathrm{CFU}_{\text {prawn }}{ }^{-1}$, respectively. All prawns injected with $1.5 \times 10^{5}$ yeast cells died within $2 \mathrm{~d}$. Pure cultures of each yeast were re-isolated from the HP and muscle tissues of moribund prawns following challenge. The control group was free of mortality and lesions. The gross signs of disease and histopathological changes found in experimentally infected prawns were similar to those in naturally infected prawns. No significant gross or histopathological differences were observed among the prawns infected with the 3 yeasts.

\section{DISCUSSION}

This investigation aimed to identify the yeast(s) most prevalent in freshwater prawns suffering from white muscle disease during the winter season in southern Taiwan. Yeasts are common in aquatic habitats, but few have been demonstrated to be pathogenic. One pathogenic species, Metschnikowia bicuspidata, infects the cladoceran Daphnia magna (Codreanu \& Codreanu-Balcescu 1981).

No differences were observed in water quality (ammonia, nitrite, and $\mathrm{pH}$ ) between the ponds of both diseased and healthy prawns. However, a surprisingly strong negative correlation existed between the percentage of infected prawns and water temperature (Lu et al. 1997). Low temperatures were found to be optimal for yeast multiplication, and they may impair prawn resistance to infection. In areas with a history of yeast infection in ponds, frequent monitoring of prawns during winter would be prudent.

The reason for the high infection rate among adult prawns is unknown. Although adult prawns have a 


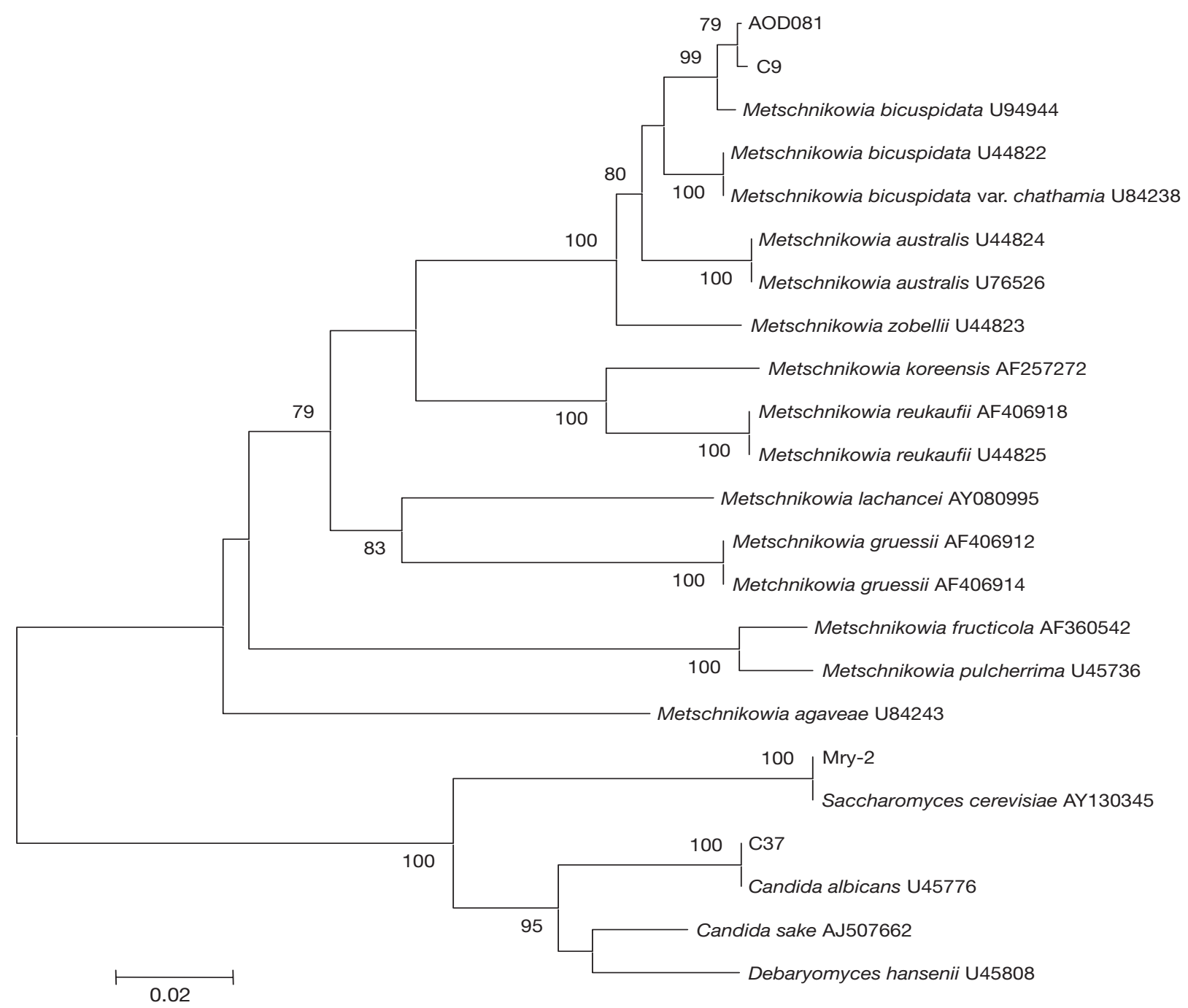

Fig. 9. D1/D2 domain sequence-based phylogenetic tree of yeast isolates from our study and from GenBank. Bars indicate genetic distance. Numbers at each node indicate percent bootstrap values. Scale represents 0.02 nucleotide substitutions per position

more mature immunological defense system (Lu et al. 1997), they are more likely to encounter yeasts in the pond water or sediments. This is due to their longevity and tendency to cannibalize prawns that are dead or moribund from severe yeast infection. Because of the high mortality related to yeast infection in adult prawns, early identification of outbreaks and tracing of the pathogens is especially important. The treatment of yeast infection in prawns is very difficult, but emergency harvest could be employed if the disease were detected early in a given population. PCR should provide a sensitive, efficient, and reliable method of distinguishing closely related strains in epidemiological studies.

Yeast infection in prawns occurs through oral or gill contact with yeast cells in the pond water or sediments (Lu et al. 1998). The yeast cells are subse- quently phagocytized by the host hemocytes, where yeast cells become encapsulated within a membranebound vacuole and remain viable while undergoing limited replication ( $\mathrm{Lu}$ et al. 1998). When the host becomes more susceptible to yeast infection as water temperatures decrease, the yeast cells may rapidly replicate inside the hemocytes, which eventually lyse and release the yeast cells. The fact that we found very high concentrations of yeast cells in the hemolymph of naturally infected prawns supports the suggestion that they can spread through the circulatory system to reach various tissues.

From previous studies, yeasts that are pathogenic for Macrobrachium rosenbergii include Candida sake (I and II), Pichia anoma, Endomyces fibuliger, and $C$. famata (Lu et al. 1998). C. sake I was the most common $(50 \%)$ yeast found in diseased prawns, followed 
by C. famata $(20 \%)$, C. sake II (16\%), P. anomala $(11 \%)$, and finally $E$. fibuliger, which was the least common $(3 \%$; Lu et al. 1998). We identified 3 pathogens, namely Metschnikowia bicuspidata, Saccharomyces cerevisiae, and C. albicans, via API 32C, conventional biochemical tests, PCR of from the D1/D2 domain of 26S rDNA, and phylogenetic analysis. It is interesting that the $S$. cerevisiae isolate had high tolerance to $\mathrm{NaCl}$ even though $M$. rosenbergii is reared in fresh water (Gläser et al. 1993). The reason why pathogens detected in our infected prawns differed from those previously reported (Lu et al. 1998) could be due to differences in methodology or circumstances of prawn cultivation.

The results from both field specimens and experimental infections provide the first confirmation that Metschnikowia bicuspidata, Saccharomyces cerevisiae, and Candida albicans infection can cause disease outbreaks in the giant freshwater prawn Macrobrachium rosenbergii. Even though we obtained a few isolates of $S$. cerevisiae and $C$. albicans, their $\mathrm{LD}_{50}$ values were $<10^{4} \mathrm{CFU}$ prawn ${ }^{-1}$ so that their virulence was similar that observed for $M$. bicuspidata. In addition, we fulfilled Koch's postulates for all 3 yeasts in $M$. rosenbergii and showed that $M$. bicuspidata is the most frequent in Taiwanese cold-weather yeast infections. Yeast-like organisms often appear as opportunistic/secondary invaders during times of immunocompromise or co-infection with other pathogens (Lu et al. 1998, Chen et al. 2003). The large variety of yeast species reported from $M$. rosenbergii and the inclusion of those rarely reported as pathogens (e.g. S. cerevisiae and Endomyces fibuliger) supports the contention that they are opportunistic pathogens. Immersion and oral challenge tests are also needed to determine natural transmission routes. In ongoing work, we will attempt to examine changes in prawn immunological parameters during the cold season and how this might affect susceptibility to yeast infections.

Acknowledgements. This study was supported by the National Science Council of Taiwan, ROC (grants NSC922313-B020-015 and NSC92-2313-B020-017).

\section{LITERATURE CITED}

Cameron A (2002) Survey toolbox for aquatic animal diseases; a practical manual and software package. Monographs MN094, Australian Centre for International Agricultural Research, Canberra

Editorial responsibility: Timothy Flegel, Bangkok, Thailand
Chen SC, Lin YD, Liaw LL, Wang PC (2001) Lactococcus garvieae infection in the giant freshwater prawn Macrobranchium rosenbergii confirmed by polymerase chain reaction and $16 \mathrm{~S}$ rDNA sequencing. Dis Aquat Org 45:45-52

Chen SC, Chen TH, Wang PC, Chen YC, Huang JP, Lin YD, Chaung HC, Liaw LL (2003) Metschnikowia bicuspidata and Enterococcus faecium co-infection in the giant freshwater prawn Macrobrachium rosenbergii. Dis Aquat Org 55:161-167

Codreanu R, Codreanu-Balcescu D (1981) On two Metschnikowia yeast species producing hemocoelic infections in Daphnia magna and Artemia salina (Crustacea, Phyllopoda) from Romania. J Invertebr Pathol 37:22-27

Felsenstein J (1985) Confidence limits on phylogenies: an approach using the bootstrap. Evolution 39:783-791

Fitch WM (1972) Towards defining the course of evolution: minimum change for a specific tree topology. Syst Zool 20:406-416

Gläser HU, Thomas D, Gaxiola R, Montrichard F, SurdinKerjan Y, Serrano R (1993) Salt tolerance and methionine biosynthesis in Saccharomyces cerevisiae involve a putative phosphatase gene. EMBO J 12:3105-3110

Jukes TH, Cantor CR (1969) Evolution of protein molecules. In: Munro HN (ed) Mammalian protein metabolism. Academic Press, New York, p 21-132

Kumar S, Tamura K, Jakobsen IB, Nei M (2001) MEGA2: Molecular Evolutionary Genetics Analysis software. Bioinformatics 17:1244-1245

Kurtzman CP, Robnett CJ (1997) Identification of clinically important ascomycetous yeasts based on nucleotide divergence in the $5^{\prime}$ end of the large-subunit (26S) ribosomal DNA gene. J Clin Microbiol 35:1216-1223

Lachance MA, Miranda M, Miller MW, Phaff HJ (1976) Dehiscence and active spore release in pathogenic strains of the yeast Metschnikowia bicuspidata var. australis: possible predatory implication. Can J Microbiol 22:1756-1761

Lu CC, Tang FJ, Yoichiro U, Kou GH, Chen SN (1997) Yeast infection in prawns (Macrobrachium rosenbergii de Man) in Taiwan. Acta Zool Taiwanica 8:33-45

Lu CC, Tang KFG, Chen SN (1998) Identification and genetic characterization of yeast isolated from freshwater prawns, Macrobrachium rosenbergii de Man, in Taiwan. J Fish Dis 21:185-192

New MB (1995) Status of freshwater prawn farming: a review. Aquac Res 3:46-65

Rzhetsky A, Nei M 1993. Theoretical foundation of the minimum-evolution method of phylogenetic inference. Mol Biol Evol 10:1073-1095

Saitou N, Nei M (1987) The neighbor-joining method: a new method for reconstructing phylogenetic trees. Mol Biol Evol 1 4:406-425

Spencer JFT, Phaff HJ, Gardner NR (1964) Metschnikowia kanienskii, sp. n., a yeast associated with brine shrimp. J Bacteriol 88:758-762

Stewart-Tull DE, Ng FK, Wardlaw AC (1984) Factors affecting the lethality of Campylobacter fetus subspecies jejuni in mice. J Med Microbiol 18:27-37

Van Uden N, Castelo-Branco R (1961) Metschnikowia zobellii sp. nov. and $M$. krissii sp. nov., two yeasts from the Pacific Ocean pathogenic for Daphnia magna. J Gen Microbiol 26:141-148

Submitted: August 8, 2005; Accepted: February 2, 2006

Proofs received from author(s): March 29, 2007 